\title{
Historical Development of IEQ in Danish Dwellings - Has Energy Efficiency Requirements Inhibited Positive IEQ Developments?
}

\author{
Lasse Rohde ${ }^{1}$, Tine Steen Larsen², Rasmus Lund Jensen², Evangelia Loukou², Kim Jønsson² \\ ${ }^{1}$ Aalborg University, Department of Civil Engineering, Aalborg, Denmark - ler@civil.aau.dk \\ ${ }^{2}$ Aalborg University, Department of Civil Engineering, Aalborg, Denmark
}

\begin{abstract}
This paper investigates developments in indoor environmental quality (IEQ) and energy efficiency over the last 150 years. Sixty-one Danish multistory dwellings were registered and scored using a newly developed IEQ assessment tool called IV20. An overview of this scoring is presented, indicating which IEQ issues have been solved, which remain unsolved, and which new ones have arisen. IEQ developments are compared to developments in energy consumption, to test the hypothesis that some initiatives to reduce energy consumption comes at the expense of occupant comfort and health. An overview of energy efficiency developments for Danish multistory dwellings is given through analysis of data from the Danish energy labelling database. The results show a solid positive development in energy efficiency and a very modest improvement in potential IEQ. Results suggest that positive IEQ developments may have been inhibited by energy efficiency initiatives and that further IEQ advances may depend on a change of political priorities.
\end{abstract}

\section{Introduction}

The European Union's 2020 and 2050 targets for the reduction of energy consumption and $\mathrm{CO}_{2}$ emissions (European Commission, 2011) signal significant changes for the building sector responsible for almost $40 \%$ of the global final energy consumption and total greenhouse gas emissions (European Commission, 2019). This political agenda has enforced energy-saving practices into national building codes in the developed world heavily influencing how we build and renovate. In some cases, this focus on energy efficiency has been at the expense of healthy and comfortable indoor environments (IE) (Roulet et al., 2006). Increasing insulation values, air tightness, and passive solar gains often result in extensive overheating in cold climates (Brunsgaard, Heiselberg, Knudstrup, \& Larsen, 2012; Larsen, Daniels, Jensen, \& Andersen, 2012; Morgan, Foster, Sharpe, \& Poston, 2015).

In many parts of the world, people spend $90 \%$ of their time indoors (Klepeis et al., 2001). Most of this time is spent at home, meaning that IEQ in dwellings has an enormous impact on the comfort, health and well-being of people. The social sustainability potential of good indoor environmental quality (IEQ) in dwellings is huge from perspectives such as work absenteeism, productivity, healthcare costs, and social equality. Thus, it may be the time to complement political agendas such as the Energy
Performance of Buildings Directive (Council of the European Union, 2002; European Parliament, 2010), with an ambition to also improve IEQ in dwellings. There is a growing political understanding that energy efficiency and IEQ should not be seen as mutually exclusive (CIBSE, 2013; Watson, 2017).

The rapidly increasing world population adds extra pressure to climate adaption requirements and acts as a driver for increased urbanisation as the current answer to high population accommodation and sustainable living. Increased urban density leads to increased exposure to noise and air pollution reducing the potential of a healthy and comfortable indoor environment. When buildings are too tall and too close, it also compromises privacy from risk of unwanted view in and reduces access to daylight, sunlight, and view out. United Nations expects two-thirds of the world's population to be located in urban centres by 2050 (United Nations, 2014). This makes the development of urban dwellings, with low-energy consumption and high-quality indoor environment, one of the keys to sustainable living in the decades to come.

The Energy Performance of Buildings Directive (Council of the European Union, 2002; European Parliament, 2010) has resulted in energy labelling for European buildings as part of the building code. Many national variations of energy efficiency assessment tools (Be18 in Denmark) calculate a theoretical energy demand for both existing and new buildings. As a result, energy-efficiency databases for buildings are well developed in a European context. However, most IEQ assessment tools are designed for evaluating new buildings only or are expensive certification options for best practice buildings (such as LEED, BREEAM, DGNB, WELL), meaning that developments in overall IEQ are mostly unknown particular for older dwellings.

The REBUS project (REBUS, 2016) has developed an IEQ assessment tool called IV20 based on simple-input calculations. The tool assesses the IEQ potential of the building, based on a range of collected building data. IV20 is designed for use in the early design stages, as opposed to assessments based on expensive and timeconsuming measurements or occupancy surveys. The independence of measurements and surveys removes bias from user responses and user behaviour and enables assessments of IEQ potential in both existing builds and unrealised design proposals. This makes the tool ideal for benchmarking samples of the existing building stock. 
This approach also allows for identification of the specific reason(s) for a certain performance in any part of the assessment, by tracing an assessment sub-score back to the building data that influence it.

This paper will compare decades of well-documented positive developments in calculated energy demand, with new data on the developments in potential IEQ in dwellings. IEQ assessment results of 61 multistory dwellings will be presented, followed by a brief discussion of the main trends. IEQ developments are then compared to overview plots from building energy certification (Danish Energy Agency - Danish building energy certification) to compare developments within IEQ and energy efficiency over time. Based on this analysis, the authors will highlight tendencies in how the building code emphasis on energy efficiency has affected the overall IEQ for multistory buildings in the last 150 years.

\section{Methods}

\section{Categorizing cases into building periods}

The analysis of Danish multistory dwellings is based on IEQ assessments of a series of case studies compared to an analysis of energy certification for multistory dwellings. This paper will use the building typology scheme TABULA (IEE Project TABULA, 2012) to organise the buildings into time periods. These periods are separated by building tradition shifts, affecting building typologies in a Danish context from 1851 and onwards. Many of these shifts are energy-consumption driven, and thus defined by the introduction of building codes with increasingly strict energy requirements. This paper investigates how energy consumption driven requirements have affected the potential IE in multistory buildings by comparing the advances in energy efficiency (using the national energy label database) with changes in IEQ in the cases assessed.

It is outside the scope of this paper to explain the differences in the individual building code requirements, but since the introduction of the first Danish energy requirements in 1961, the focus has been on limiting energy consumption for heating. This has primarily been done through improved insulation levels and later through heat recovery of exhaust air and improved air tightness. Since the '98 building code, there has been a focus on increasing passive solar gains, primarily through increased glazed areas, window orientation optimised for solar gains and higher window g-values. Also, the 2020 building code requires that windows have a neutral or positive energy balance in the heating season (E-ref in the Danish Building Regulations). These changes are expected to have influenced the indoor environment on several levels, in particular, thermal IE which is directly tied to heating demands, but also for visual IE and indoor air quality (IAQ) as a result of changed window areas, new window properties and the introduction of mechanical ventilation. The analysis of the IEQ assessed cases would focus mainly on thermal IE, visual IE and IAQ, as many energy-efficiency initiatives influence air change rates, daylight conditions, or thermal comfort variations.

\section{Sampling and data collection procedure}

Sixty-one Danish multifamily apartments were rated using the IV20 tool for assessment of IEQ in multistory dwellings. The cases were selected on three criteria to ensure good representation of the Danish multistory dwelling building mass with the available resources;

1) Location within one of the largest Danish cities (see Introduction for increased urbanisation arguments),

2) Year of construction spread across as many building code periods as possible (minimum 5 cases for each period to be included in the analysis),

3) Availability of drawings and access to the dwellings.

Registrations were made in November/December 2017 by a team of three assessors to minimise the risks of variations in the use of the tool. Data for the case studies were collected through a combination of on-site registration, visual inspection, analysis of drawings and various online databases. The on-site registration was performed using a registration template organised for a systematic registration of IV20 input on site level, building level, dwelling level and room level. The online databases include building project archives, aerial photographs, and digital maps for site-specific traffic noise and pollution levels.

\section{Dataset - key figures}

The cases registered covers 8 of the 10 Danish energyrelated building typologies identified in the Danish contribution to the TABULA project (Wittchen \& Kragh, 2012). The period before 1851 is not included as it has no energy labels for multistory dwellings before 1851 . The 2007-2011 period was excluded as it was not possible to obtain access to at least 5 cases for the IEQ assessment.

The IEQ cases cover buildings constructed from 1883 to 2016 (134 years), and are split between 3 of the 4 largest Danish cities as follows; Aalborg area - 27 cases, greater Copenhagen area - 23 cases, and greater Aarhus area - 11 cases. Year of construction ranges for the periods are as follows: 1851-1930 (period 1); 1931-1950 (period 2); 1951-1960 (period 3); 1961-1972 (period 4); 1973-1978 (period 5); 1979-1998 (period 6); 1999-2007 (period 7); 2007-2011 (period 8); 2011-onwards (period 9).

Building energy labels were extracted from the national energy label database (Energistyrelsen) for the 179280 multistory dwellings in the period from 1851 to 2015 (165 years). The analysed energy labels span across the nine different Danish building periods listed above. Period 4 marks the introduction of the first energy requirements in BR61, with period 5 through 9 being defined by increasingly tightened requirements for BR72, BR77, BR98, BR08 and BR10.

\section{Results}

\section{IV20 cases - IEQ overview tendencies}

Figure 1 shows the IV20 score for air quality, thermal IE, and visual IE respectively, for each of the 61 registered cases listed by year of construction. Note that while 


\section{IV20 Overall score}

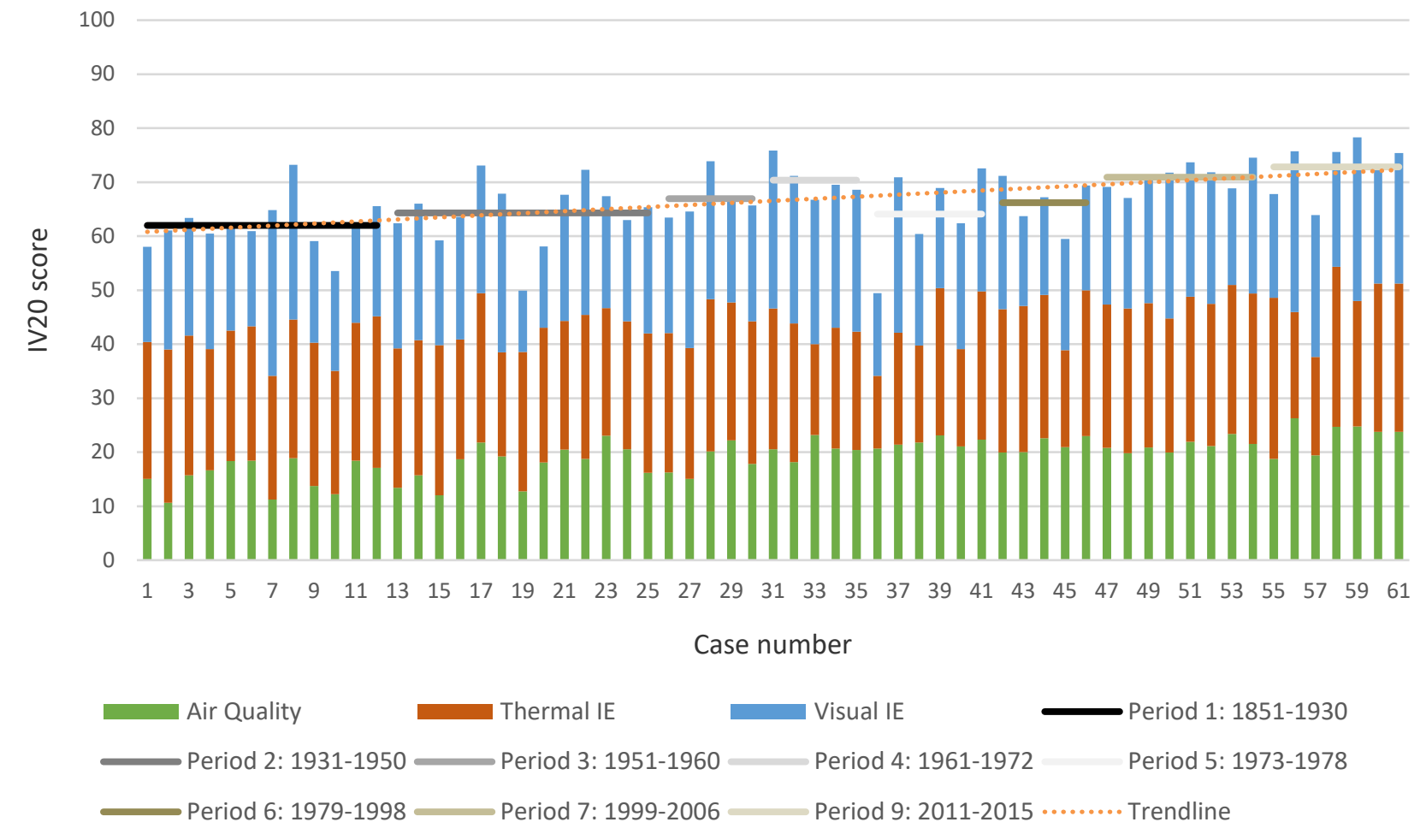

Figure 1: IV20 score for 61 registered multifamily dwellings (chronologically ordered by year of construction) showing contributions from air quality, thermal IE, and visual IE, as well as averaged values for eight different building periods.

acoustic IE is part of IV20 assessment and weighted equally with the other three domains, it is not part of the current analysis that compares developments in IEQ with improvements in energy efficiency. Energy efficiency improvements driven by building code requirements influence the performance of IAQ, thermal IE and visual IE directly, but have a more indirect influence on acoustic IE. Better insulated and more airtight envelopes are expected to reduce noise from outside the building, but due to space conservation reasons, acoustic IE will not be discussed further. The three areas analysed contribute equally to the overall IV20 scores shown for this paper.

The data in Figure 1 shows modest improvements in IEQ over time as highlighted by the trend line (significant tendency, t-test: $\mathrm{p}=0.0007)$. The earliest period (18511930) has the lowest average IV20 score of 62 pts (out 100 pts), while the most recent period (2011-2015) has the highest average of approx. $73 \mathrm{pts}$. The improvements over time are relatively small compared to the differences between individual cases, such as the 1973-1978 period containing both the lowest of all scores at approx. 49 pts as well as a score of approx. 73 pts positioned in the top third. The significant inter-period variations suggest that IE variations are more dependent on case-specific conditions than the requirements of the applied building code at construction. The large variations within building periods call for greater sample size, allowing for further statistical analysis. However, a tendency for development can still be found in the analysed cases.

\section{Energy labels - Energy-efficiency tendencies}

Figure 2 shows developments of energy efficiency for multifamily dwellings over the last 165 years, by plotting the averaged primary energy demand by construction year (using primary energy factors from BR10). The data plotted comes from the Danish building energy certification, and includes 179,280 Danish multifamily dwellings constructed between 1851 and 2015 .

The data in Figure 2 shows a very significant tendency towards drastically decreasing energy demands over time (t-test: $p=2.2 \cdot 10^{-16}$ ), particularly from 1961 to 2015 , with a factor 2.63 improvement (averaged yearly energy demand in $\mathrm{kWh} / \mathrm{m} 2 /$ year; period 3: 117.8 and period 9: 44.8). While the average energy demand is unchanged for the first 100 years analysed (averaged yearly energy demand in $\mathrm{kWh} / \mathrm{m}^{2} /$ year; period $1: 120.2$, period 2: 120.3 , and period 3: 117.8) it has dropped dramatically in the most recent 50 years. The most significant drop in the almost 25\% drop from period 3 (1951-60: 117.8 $\mathrm{kWh} / \mathrm{m}^{2} /$ year) to period 4 (1961-1972: 90.3 $\mathrm{kWh} / \mathrm{m}^{2} /$ year), where the first energy requirement was introduced with the BR61 building code.

Energy demand reduction has been a significant focus in the most recent Danish building codes, which is reflected in an increasingly lowered energy demands for period 7, 8 and 9 (1999-2015). The average energy demand by construction year is effectively halved in just two decades from 91.2 to $44.8 \mathrm{kWh} / \mathrm{m}^{2} /$ year with the introduction of the BR98, BR08 and BR10 building codes. 


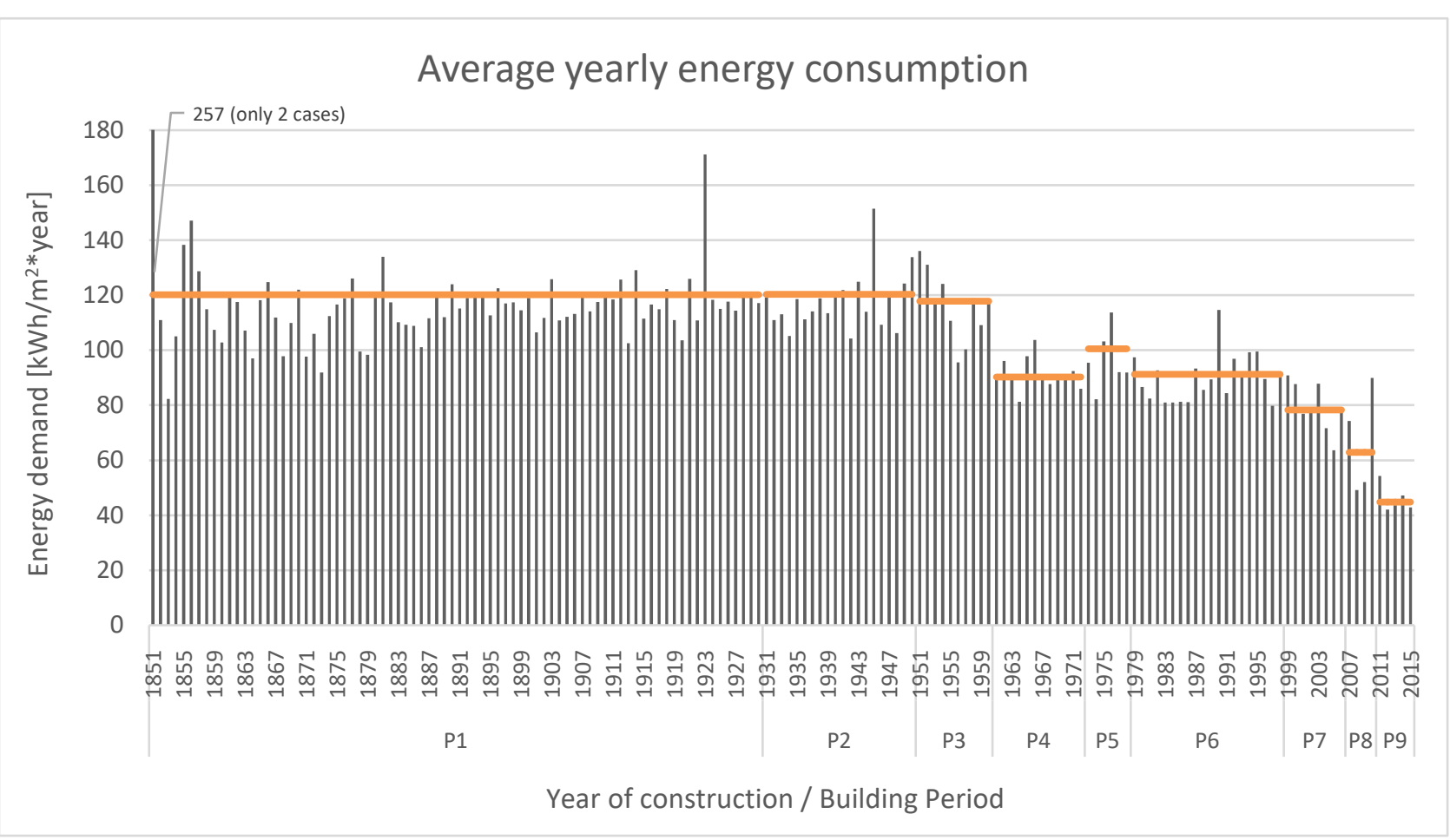

Figure 2: Calculated primary energy demand for 179,280 Danish multifamily dwellings plotted as averaged values by year of construction from 1851 to 2015. The orange lines show time period averages for each of the nine different building codes.

Going further back, we get a factor 2.69 improvement of the average energy demand by period between the 19311950 period $\left(120.31 \mathrm{kWh} / \mathrm{m}^{2} /\right.$ year $)$ and the $2011-2015$ period (44.78 $\mathrm{kWh} / \mathrm{m}^{2} /$ year). When comparing this to the modest factor 1.13 improvement $(64.3 \%$ in $1931-1950$ period, to $72.8 \%$ in the $2011-2015$ period) in indoor environment in the same period (as exemplified by the IV20 score in Figure 1), it becomes very clear that the building code requirements has prioritized energy efficiency above indoor environmental improvement.

\section{IV20 cases - IEQ area by area}

More than two-thirds of the 10.8 pts overall IV20 score increase over time can be accredited to IAQ improvements, with an overall score contribution ranging from 15.5 pts from the earliest period (1851-1930) to 23.1 pts in the latest period (2011-2015) (see Figure 1). The rest of the overall score increase is from a slight improvement in visual IE ranging from 21.2 pts from the earliest period (1851-1930) to $24.7 \mathrm{pts}$ in the latest period (2011-2015). Thermal IE shows no improvements over time, with an average overall contribution of $25.2 \mathrm{pts}$ from the earliest period (1851-1930) to $25.1 \mathrm{pts}$ in the latest period (2011-2015) and an average of 24.7 pts across all time periods.

\section{Tendencies - IAQ}

Although modest, air quality improvements are relatively stable across all periods, with the most significant improvements in the range of period 1 through 4 , and again from period 7 to 8 . The main reason for the positive development in the early periods are due to air change improvements (IAQ2 in Figure 3 below), through improved conditions for natural ventilation. The boost from period 7 to 9 comes from the introduction of mechanical ventilation with fixed ventilation rates in the later time periods ( 7 out of 10 cases with mechanical ventilation is from period 9;2011-2015) improving scores for both air change and particular matter in intake air (IAQ2 and IAQ1 in Figure 3 below).

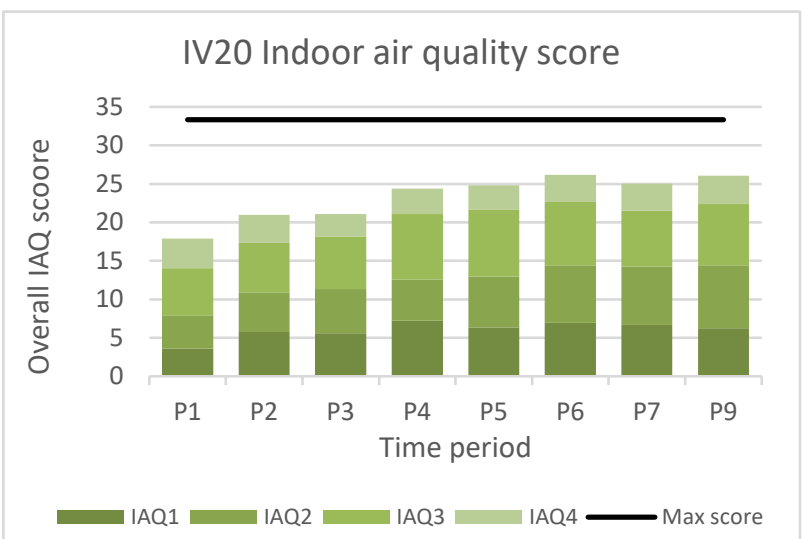

Figure 3: Averaged overall IAQ score for eight different periods, showing contributions from four different IAQ areas.

Decreased adverse effects of air polluting indoor activities, make a small contribution to the overall IAQ improvements, although the two most recent time periods indicate a small step back. The positive part of this development comes from preinstalled components with a beneficial influence on the IAQ such as stove type (combustion-based vs electric), and exhaust hood availability and efficiency. The recent negative development is due to fewer modern apartments (1999+) having covered spaces for drying clothes leading to increased particle and humidity loads. 


\section{Tendencies - Thermal IE}

The data shows no overall thermal IE improvements throughout more than 150 years, despite advances in envelope air-tightness and insulation levels. Interestingly, 7 out of 8 cases with an overall thermal score below 20 pts are constructed within the last 50 years (period 4-9; 1961-2015). The reason for this lack of improvement is primarily due to issues of too high summer temperatures (evaluated through a summer comfort calculation) (TER1 in Figure 4 below), that is almost non-existing until energy requirements were introduced in the 1961 building code. Issues with high temperatures are the direct result of building code demands to lower energy consumption for heating; heating demand reduction initiatives (such as reductions in infiltration, line losses and lowered Uvalues for walls and windows) and passive heat gain strategies (such as heat recovery and increased solar gains). Analysis of the IV20 cases shows that areaweighted average U-values in the first three periods (1851-1960) is 0.91. After 1961, however, the average Uvalue decreases steadily by period down to 0.24 for cases in the latest three periods (1979-2015).

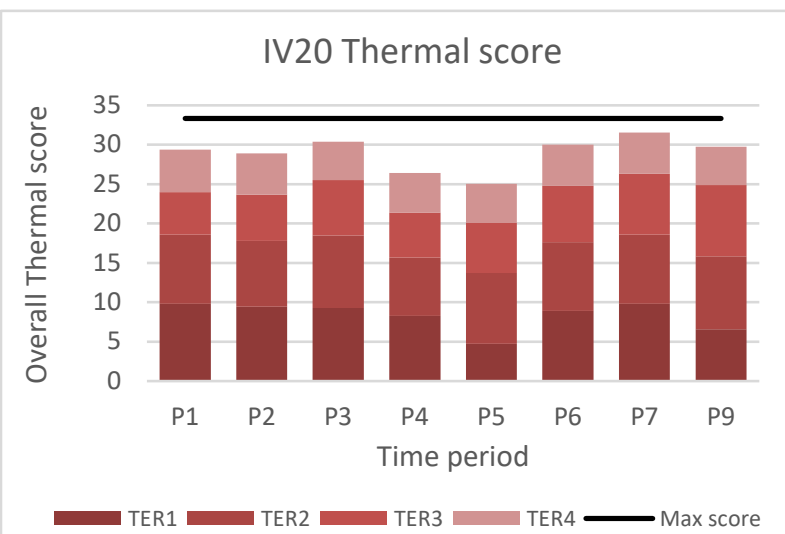

Figure 4: Averaged overall thermal IE score for eight different periods, showing contributions from four different thermal areas.

These issues offset the positive developments in winter comfort (TER3 in Figure 4), mainly from lowered draft risk because of improved air tightness and a lowered risk of downdraft from significantly lowered window Uvalues, ranging from 2.5 in the first two periods (18511950) to approx. 0.8 in period 9 (2011-2015). Improvements from pre-heated intake air (here mainly from mechanical ventilation with heat recovery) make a substantial difference in period 9 (2011-2015) resulting in the best winter comfort sub-scores.

\section{Tendencies - Visual IE}

Visual IE shows modestly increasing scores over the analysed time periods, with period 4 (1961-1972) breaking the overall tendency by being the highest scoring period by a margin. This development is reflected clearly in the daylight assessment (VIS1 in Figure 5), showing daylight quantity and distribution improving gradually over time, but with period 4 (1961-1972) being far above the trend line and period 5 (1973-1978) being far below.
The VIS1 sub-score for daylight quality (colour falsification) dampens the positive developments in daylight score, by penalising projects with a sub-par colour rendering (Ra-value). More than half of the projects in period 5, 7 and 9 are penalized for colour falsification (12 out of 21 projects), compared to just 1 in 20 for the other time periods ( 2 out of 40 cases). The main contribution of this colour falsification comes from window coating or window film (low g-value) designed to limit passive solar gains to fight the risk of too high temperatures.

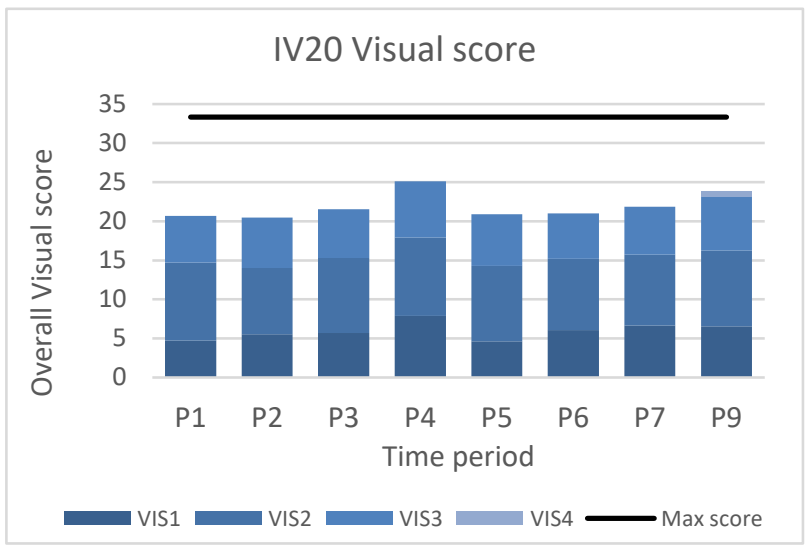

Figure 5: Averaged overall visual IE score for eight different periods, showing contributions from four different visual areas.

The developments in daylight are explained mainly by an increased glazed area starting with a window to wall area of $28 \%$ in the first two periods (1851-1951) to $41 \%$ for period 3-9. Tendencies are less clear for the other visual IE assessment topics such as Positive solar exposure (VIS2), View out quality and View in risk (VIS3), and they will not be discussed in this paper.

\section{Discussion}

The IV20 tool was developed for the early-stage assessment of renovation potential of multistory dwellings, but could potentially contribute to future labelling of IEQ of all Danish dwellings. The presented data for IEQ assessment is, however, limited by the modest sample size. Although the assessment is based on simple input, large quantity registration is timeconsuming, and it will require mandatory IEQ labelling to achieve a sample size comparable to the almost 180,000 energy labels used for the energy efficiency analysis.

The IEQ assessments of the 61 cases presented is made using a beta version of the IV20 tool. While the assessment methodology and criteria of interest are set, the inter-area weightings and scoring may change slightly in the final version (expected ultimo 2019).

The IV20 tool is designed to assess the current conditions of a building, but for the historical perspective analysis of this paper, it would be more appropriate to reset 'wear and tear' to the time of erection. For instance, deteriorated window sealants can negatively influence the score for drafts in older buildings, but the influence on the scores presented here is negligible. 
Most of the older case buildings have been partially renovated over the years, and in the case of recent and deep renovations, this may blur the results of both the IEQ and energy efficiency analyses slightly. For the present comparison of IEQ vs energy efficiency, this has very little influence, as the number of deep energy renovations is relatively small (average calculated energy demand for renovated projects is approx. $107 \mathrm{kWh} / \mathrm{m}^{2} /$ year vs approx. $105 \mathrm{kWh} / \mathrm{m}^{2} /$ year for non-renovated projects) .

\section{Conclusion}

The analyses of the energy labelling database show a strong positive development within energy efficiency in the last approx. 50 years, boasting a factor of 2.63 improvement in the average calculated energy demand from period 3 to period 9. The majority of this improvement is in the last approx. 37 years from a tightened energy requirement in 1978, with a factor of 2.24 improvement from period 5 to period 9. This tendency follows tightened legislatorial demands from the introduction of the first building code energy demands (period 4), to a series of ambitious national energy frame reductions still being implemented.

IEQ assessments of the 61 cases indicate a very modest improvement in overall IEQ over time. This research shows that the average level of the main IEQ areas has not declined and that IAQ has improved slightly over time. Criteria level analysis shows that IAQ has been positively affected by ventilation strategy changes, supporting improvements in ventilation rates for natural ventilation, bathroom ventilation and the introduction of mechanical ventilation with filtering for newer buildings. Thermal IE has been affected by heat demand reduction initiatives, resulting in reduced comfort issues with drafts, but increased issues with overheating. Visual IE has mainly been affected by larger glazed areas, and a change in window components is contributing to improved daylight levels but also resulting in colour falsification that negatively affects the quality of daylight and view out.

The presented results indicate that the most recent building tradition has managed to improve energy efficiency significantly without negative consequences for the indoor environment as a whole. Improvements include significantly reduced issues with drafts, improved daylight access, and increased dilution and air filtration. However, increased window areas have introduced significant issues with too high room temperatures and new challenges such as exposure to view in (reduced privacy) and colour falsification through coated glass.

The average percentile improvement of IEQ over 150 years $(+13 \%)$ is more than a magnitude lower than that for energy efficiency $(+169 \%)$, which is fueled by decades of political and legislatorial priorities. While the average overall IEQ has not declined over the last 150 years, this study suggests that the building industry may have inhibited positive developments in IEQ through a narrow priority of energy-efficiency. For instance, the risk of overheated apartments is negatively influenced by energy reduction initiatives to reduce heat losses and increase gains. If urbanisation is the solution to increasing world population and energy conservation for living and transportation, then multistory dwellings have a considerable influence on the comfort and health of future generations - and should be a topic of interest for architects, engineers and politicians.

\section{Acknowledgements}

The work presented in this paper was made possible by the support of the dedicated partnership REBUS Renovating Buildings Sustainably. The partnership is funded by Innovation Fund Denmark (5151-00002B), Realdania (PRJ-2015-00481) and The Landowners' Investment Foundation (in Danish Grundejernes Investeringsfond, 9025410).

The authors would like to thank Energistyrelsen for providing data on calculated energy demands, and Himmerland Boligforening for providing access to many of the registered dwellings. Also, thanks to the master students at Aalborg University who worked with the original registration of the 61 cases: Aurelian Paduraru, Julius César Peralta Hedin and Rasmus Samuel Thode Christensen.

\section{References}

Brunsgaard, C., Heiselberg, P., Knudstrup, M. -a., \& Larsen, T. S. (2012). Evaluation of the Indoor Environment of Comfort Houses: Qualitative and Quantitative Approaches. Indoor and Built Environment, 21(3), 432-451. https://doi.org/10.1177/1420326X11431739

CIBSE. (2013). TM54: Evaluating operational energy perfomance of buildings at the design stage (pp. 130). pp. 1-30. https://doi.org/978-1-906846-38-1

Council of the European Union. (2002). Directive 2002/91/EC of the European Parliament and of the Council of 16 December 2002 on the energy performance of buildings. Official Journal Of The European

Union. https://doi.org/10.1039/ap9842100196

European Commission. (2011). A Roadmap for moving to a competitive low carbon economy in 2050 . In Change. https://doi.org/10.1002/jsc.572

European Commission. (2019). The Energy Performance of Buildings Directive - Fact Sheet. Retrieved January 8, 2020, from European Commission website: https://ec.europa.eu/energy/sites/ener/files/documents /buildings_performance_factsheet.pdf

European Parliament. (2010). Directive 2010/31 EU EPBD-recast.

IEE Project TABULA. (2012). IEE Project TABULA. Retrieved December 21, 2018, from http://episcope.eu/iee-project/tabula/

Klepeis, N. E., Nelson, W. C., Ott, W. R., Robinson, J. P., Tsang, A. M., Switzer, P., ... Engelmann, W. H. (2001). The National Human Activity Pattern Survey (NHAPS): a resource for assessing exposure to environmental pollutants. Journal of Exposure 
Analysis and Environmental Epidemiology, 11(3), 231-252. https://doi.org/10.1038/sj.jea.7500165

Larsen, T. S., Daniels, O., Jensen, R. L., \& Andersen, M. R. (2012). EnergiParcel-Projektet: Målinger og analyse af energiforbrug og indeklima i 4 danske parcelhusrenoveringer (The EnergyParcel Project: Measurements and analysis of energy consumption and indoor environment in four renovated Danish single-family homes). Retrieved from Department of Civil Engineering, Aalborg University website: http://vbn.aau.dk/en/publications/id(89900302-878c43f6-bb46-741dc39bfa0a).html

Morgan, C., Foster, J. A., Sharpe, ; T, \& Poston, ; A. (2015). OVERHEATING IN SCOTLAND: LESSONS FROM 26 MONITORED LOW ENERGY HOMES. In J.-L. Scartezzini (Ed.), CISBAT (pp. 167172). Retrieved from https://infoscience.epfl.ch/record/213311/files/2_MO RGAN.pdf

REBUS. (2016). REBUS - Renovating Buildings
Sustainably 2016-2020. Retrieved November 4, 2019, from http://rebus.nu/

Roulet, C. A., Flourentzou, F., Foradini, F., Bluyssen, P., Cox, C., \& Aizlewood, C. (2006). Multicriteria analysis of health, comfort and energy efficiency in buildings. Building Research and Information. https://doi.org/10.1016/0096-3003(92)90126-L

United Nations. (2014). World Urbanization Prospects: The 2014 Revision. Retrieved from https://esa.un.org/unpd/wup/publications/files/wup20 14-report.pdf

Watson, K. J. (2017). Developing wellbeing valuation practices in the built environment. CIBSE ASHRAE Technical Symposium, (April), 1-12. Retrieved from https://www.researchgate.net/publication/318419242 Developing_wellbeing_valuation_practices_in_the built_environment

Wittchen, K., \& Kragh, J. (2012). Danish building typologies: Participation in the TABULA project. In SBi 2012:01. 